\title{
Difference in Stability Between Edge and Center in a Rutherford Cable
}

\author{
G. P. Willering, A. P. Verweij, C. Scheuerlein, A. den Ouden, and H. H. J. ten Kate
}

\begin{abstract}
Keystoned superconducting Rutherford cables are widely used in accelerator magnets like in the LHC at CERN. An essential requirement in the cable design is its stability against local heat releases in the magnet windings originating from for example, strand movement or beam loss. Beam loss is the highest at the coil inner radius of the magnet, where also the magnetic field peaks. Also the local compaction of the cable is maximum here and hence the helium content minimum. When performing stability measurements on several superconducting $\mathrm{Nb}$-Ti cables used in LHC dipole and quadrupole magnets, we observed that the stability against point-like heat disturbances is much worse very close to the cable edges as compared to the central part of the cable. The main reason is related to the geometry of the cable causing variation of many parameters across the cable width, like inter-strand electrical resistance, inter-strand heat conductivity, cooled strand surfaces and RRR. In this paper we show results of new stability experiments and thoroughly compare the data with results obtained with the numerical network model CUDI, which is updated for stability simulations.
\end{abstract}

Index Terms-Magnets, minimum quench energy, stability, superconducting cables.

\section{INTRODUCTION}

$\mathbf{M}$ ULTIPLE experiments on the stability against local disturbances in superconducting Rutherford cables have been performed [1], [2]. Commonly the central part of the flat side of the cable is subjected to a global heat pulse. In recent measurements at CERN in the FRESCA [3] cable test station, we found, however, that the Quench Energy $(\mathrm{QE})$ of a cable can be more than one order of magnitude smaller at the thin and thick edges as compared to the center of the cable.

The stability of a superconducting cable against local heat disturbances is in general described by a curve presenting the $\mathrm{QE}$ as a function of the scaled current $\left(I / I_{\mathrm{c}}\right)$. Fig. 1 shows an example of QE measurements at $4.3 \mathrm{~K}$ and $6 \mathrm{~T}$ performed on two cable samples where by heaters located at the edge and at the center are triggered respectively. Sample 1 is a non-heat treated, cored LHC type II cable and sample 2 is a heat treated, un-cored LHC type I cable. We observed this phenomenon in all eight cables that we tested, namely an LHC type I, LHC type II, and cored LHC type II, subjected to various heat treatments. Furthermore, the effect is present in cables exhibiting both Helium I and Helium II bath cooling.

Manuscript received August 28, 2007.

G. P. Willering and H. H. J. ten Kate are with CERN, Geneva, Switzerland. They are also with the University of Twente, Enschede, the Netherlands (e-mail: gerard.willering@cern.ch).

A. P. Verweij and C. Scheuerlein are with CERN, Geneva, Switzerland

A. den Ouden is with the University of Twente, Enschede, the Netherlands.

Digital Object Identifier 10.1109/TASC.2008.920561

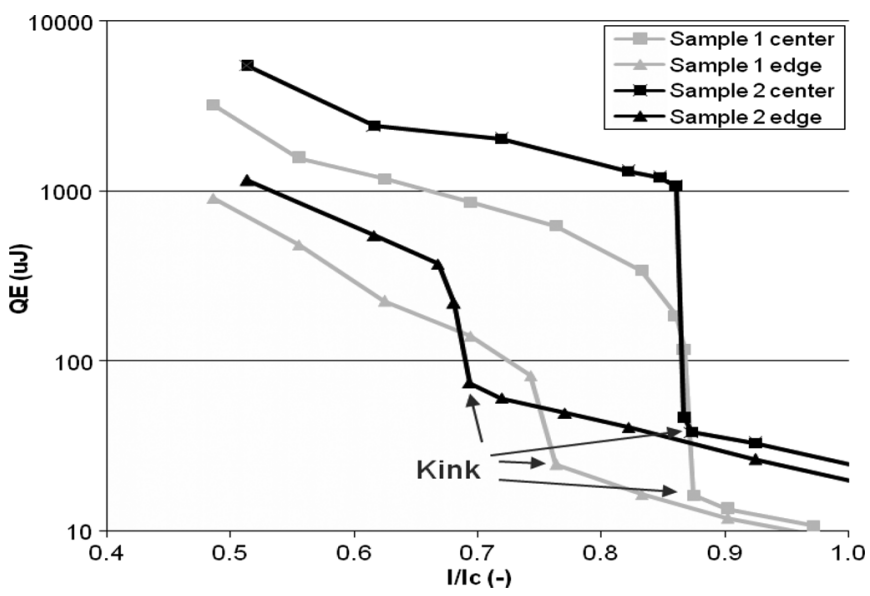

Fig. 1. Example of measurement results of the difference in stability of the cable when triggering center or edge heaters for two samples. Note that the operating current for LHC type I cable is at $I / I_{\mathrm{c}}=0.56$ and for LHC type II cable at $\mathrm{I} / \mathrm{I}_{\mathrm{c}}=0.62$ both at $1.9 \mathrm{~K}$. The operating point for FAIR SIS-300 will be at $I / I_{\mathrm{c}}=0.58$ at $4.7 \mathrm{~K}$.

Normally such a curve exhibits a sharp 'kink' separating two distinctive stability regimes. We call the current at which this kink occurs $I_{\text {kink }}$. Regime I is the high $I / I_{\mathrm{c}}$ regime, at the right side of the kink, where stability behavior is similar to the behavior of a single strand. Regime II is the low $I / I_{\mathrm{c}}$ regime at the left side of the kink, where current redistribution to adjacent strands increases the stability [4]. In Fig. 1 it is clearly shown how the stability varies between the edge and the center of the cable.

The lower stability at the edges as compared to the centre is of high importance for accelerator magnets, because the thin edge is subjected to the highest magnetic field and to the largest heat deposition from synchrotron radiation. To optimize the stability of a cable, one should chose the operating point clearly at the left side of the kink, and maximize the quench level in Regime II.

In this paper we show measurement results of the stability at the cable edges as compared to the center. We will limit ourselves here to heat treated, stainless steel cored LHC type II cables operating at $4.3 \mathrm{~K}$ and $6 \mathrm{~T}$. More details can be found in [5] where this sample is referred to as "high- $R_{\mathrm{a}}$ ". Design and measured parameters of this cable sample are listed in Table I. The difference in center and edge stability is explained by variations in the geometry across the cable width, namely the void fraction $v$, the inter-strand contact surface $A_{\mathrm{a}}$, (and hence the interstrand electrical resistance $R_{\mathrm{a}}$, and the inter-strand heat conductivity $k_{\text {is }}$ ), and the cooled strand surfaces $A_{\mathrm{He}}$. Also strand deformation affects the local RRR value. Details concerning the cable geometry will be presented in Section II. Results of simulations with the network program CUDI [6] are presented in Section IV. 
TABLE I

DESIGN PARAMETERS OF STRAND AND CABLE

\begin{tabular}{|c|c|}
\hline \multicolumn{2}{|c|}{ Strand } \\
\hline Strand diameter & $0.825 \mathrm{~mm}$ \\
\hline Filament diameter & $6.0 \mu \mathrm{m}$ \\
\hline Filament twist pitch & $15 \mathrm{~mm}$ \\
\hline $\mathrm{Cu} / \mathrm{Nb}$-Ti ratio & 1.95 \\
\hline Strand coating & Sn-Ag (Staybrite) \\
\hline Critical current density $J_{\mathrm{c}}$ & $2700 \mathrm{~A} / \mathrm{mm}^{2}(5 \mathrm{~T}, 4.2 \mathrm{~K})$ \\
\hline Critical current density $J_{\mathrm{c}}$ & $2130 \mathrm{~A} / \mathrm{mm}^{2}(6 \mathrm{~T}, 4.2 \mathrm{~K})$ \\
\hline \multicolumn{2}{|c|}{$\begin{array}{c}\text { Rutherford Cable } \\
\end{array}$} \\
\hline Strand number & 36 \\
\hline Transposition pitch & $100 \mathrm{~mm}$ \\
\hline Width & $15.1 \mathrm{~mm}$ \\
\hline Thickness, thin edge & $1.362 \mathrm{~mm}$ \\
\hline Thickness, thick edge & $1.598 \mathrm{~mm}$ \\
\hline Mid-thickness & $1.480 \mathrm{~mm}$ \\
\hline Core & $\begin{array}{l}13 \mathrm{~mm} \text { wide, } 25 \mu \mathrm{m} \text { thick, } \\
\text { stainless steel } 304\end{array}$ \\
\hline Crossover resistance $R_{\mathrm{c}}$ & $20 \mathrm{~m} \Omega$ \\
\hline Treatment & $\begin{array}{l}4 \mathrm{~h} \text { at } 200^{\circ} \mathrm{C} \text { in } \mathrm{N}_{2} \text { gas } \\
+10 \mathrm{~h} \text { at } 200^{\circ} \mathrm{C} \text { in air }\end{array}$ \\
\hline \multicolumn{2}{|c|}{ Measured values } \\
\hline Adjacent resistance $R_{\mathrm{a}}$ & $600-700 \mu \Omega$ \\
\hline Average RRR value & 245 \\
\hline Critical current $I_{\mathrm{c}}$ & $14,741 \mathrm{~A}(6 \mathrm{~T}, 4.3 \mathrm{~K})$ \\
\hline
\end{tabular}

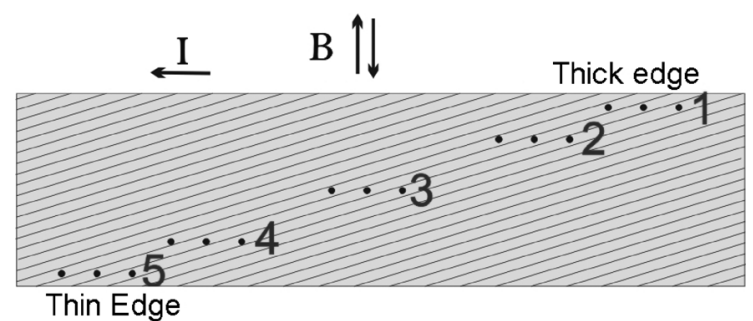

Fig. 2. The position of the heaters across the width of the cable. There are five heaters per strand on three neighboring strands with heaters numbered 1 closest to the thick edge and heaters numbered 5 closest to the thin edge.

\section{Measurement SetuP}

Measurements were performed in FRESCA on a 2.4 meter long cable sample with the characteristics given in Table I. We use graphite paste heaters to give a short $(<1 \mathrm{~ms})$ point-like heat disturbance to one strand of the cable. Energy is deposited in the strand by applying a squared electrical pulse with a duration of $100 \mu \mathrm{s}$ and power up to $40 \mathrm{~W}$. Only the heat entering the strand before the quench decision moment (QDM) takes place has to be taken into account. The scaling factor $F_{\mathrm{sc}}$ is defined as the ratio between the effective quench energy $(\mathrm{QE})$ and the input pulse energy $\left(E_{\text {inp }}\right)$. As discussed and justified in [7] we will apply $F_{\mathrm{sc}}=0.4$ in Regime I and $F_{\mathrm{sc}}=0.9$ in Regime II. In Regime $\mathrm{I}$, the QDM is just at the end of the pulse at $100 \mu \mathrm{s}$, where only a part of the heat has entered the cable. In Regime II QDM is at 0.5 to $5 \mathrm{~ms}$, where the pulse has time to enter the cable and only about $10 \%$ loss has to be accounted for. For more details on the heater production and their characteristics, see [5].

Five heaters per strand are positioned on three consecutive strands as shown in Fig. 2. In this way the stability variation across the cable width can be measured. The distance from the thin edge of the cable to the heaters is given in Table II.

Adhesive Kapton tape is wrapped around the cable, see Fig. 3, completely covering the external sides of all strands. Due to the
TABLE II

HEATER POSITIONING

\begin{tabular}{cc}
\hline \hline Heater number & Distance from the thin edge $(\mathrm{mm})$ \\
\hline 1 & 14.6 \\
2 & 11.5 \\
3 & 7.5 \\
4 & 3.5 \\
5 & 0.5 \\
\hline \hline
\end{tabular}

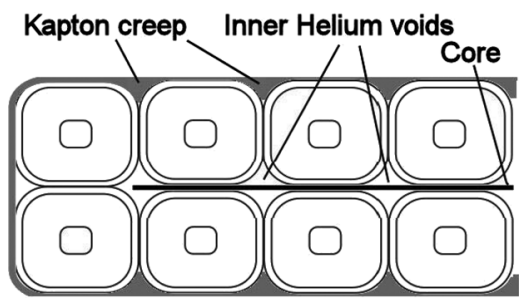

Fig. 3. Schematical partial cross-section of the cable with the wrapping of the adhesive Kapton around the cable and the assumed Kapton creep in the outer voids. Note that this insulation scheme is not the same as used in the LHC dipoles and in the FAIR SIS-300 dipoles.
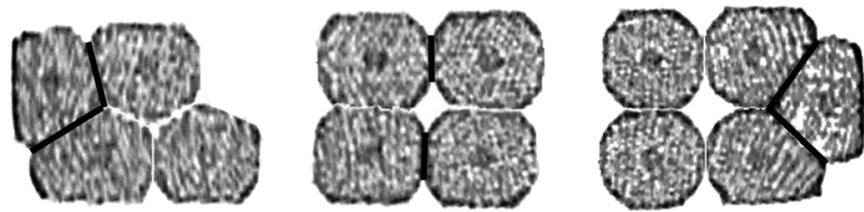

Fig. 4. Three partial cross-sections of an LHC type I Nb-Ti cable, made with neutron tomography. From left to right the thin edge, the center and the thick edge of the cable. Emphasized with a black line are the adjacent contact surfaces.

pressure of $50 \mathrm{MPa}$ on the flat surface of the cable we assume that Kapton creep blocks the outer voids.

\section{CABle Geometry}

Keystoned Rutherford type cables are widely used for winding accelerator magnets because the keystone angle allows the cables to be stacked more naturally around the aperture. During cabling the strands are forced into position by 4 cylindrical rollers to give the exact cable dimensions. Due to rolling, the strands are compressed and deformed. The strand deformation is highest at the edges, and especially at the thin edge [8]. As a result of the keystone angle, the compaction factor increases from the thick edge towards the thin edge. In order to quantify this effect, neutron tomography is performed on a Rutherford LHC type I cable (without core). Along a length of $27 \mathrm{~mm}$ one cross-section was produced every $13.5 \mu \mathrm{m}$. Fig. 4 shows three partial cross-sections. From combining multiple cross-sections, the parameters $v_{\mathrm{i}}, A_{\mathrm{He}, \mathrm{i}}$, and $A_{\mathrm{a}}$ can be deduced. $A_{\mathrm{He}, \mathrm{i}}$ is the free surface of the strand that is in contact with the inner void in $\mathrm{mm}^{2}$ per meter of strand length. $A_{a}$ is the touching surface of two adjacent strands in $\mathrm{mm}^{2}$ per meter of strand length, emphasized by a black line in Fig. 4. $v_{\mathrm{i}}$ is the inner void volume in $\mathrm{mm}^{3}$ per meter of strand length. Fig. 5 shows the results for $A_{\mathrm{He}, \mathrm{i}}, v$ and $A_{\mathrm{a}}$ after averaging along the cable length.

The curves clearly show the general effect of the keystone angle on $A_{\mathrm{a}}$ and $A_{\mathrm{He}}$, with a striking difference at the edges. 


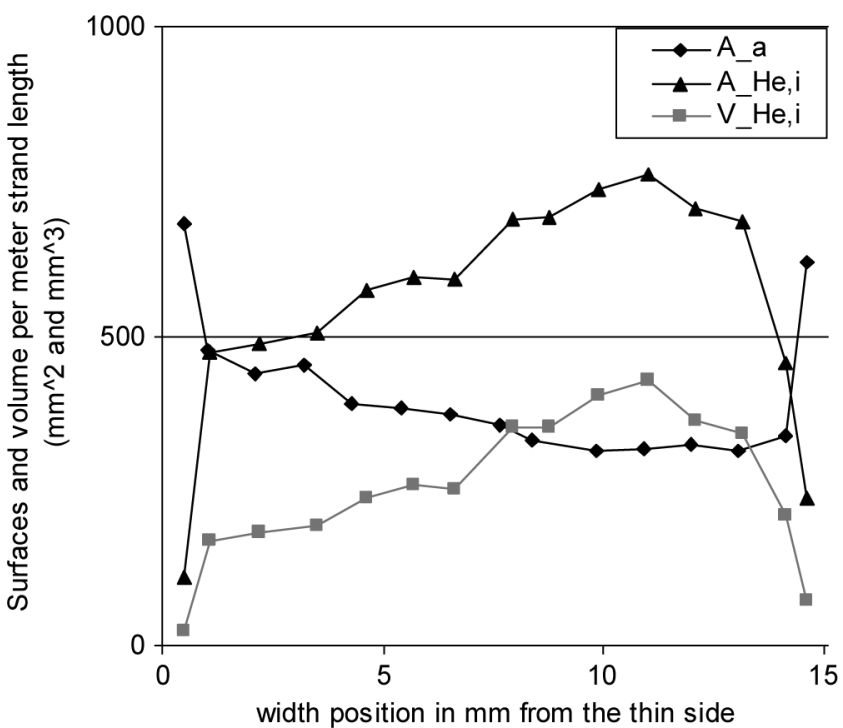

Fig. 5. Variation of $\mathrm{V}_{\mathrm{He}, \mathrm{i}}, \mathrm{A}_{\mathrm{He}, \mathrm{i}}$ and $\mathrm{A}_{\mathrm{a}}$ across the width of the cable.

At the edges the inner voids are very small. Furthermore, $A_{\mathrm{a}}$ is more than twice as large for the edge sections as compared to the center strands.

It is assumed that $k_{\text {is }}$ increases for increasing $A_{\mathrm{a}}$, and that $R_{\mathrm{a}}$ decreases for increasing $A_{\mathrm{a}}$. At the same time it is assumed that $k_{\text {is }}$ and $R_{\mathrm{a}}$ increase and decrease, respectively, for increasing pressure onto the contact. A pressure of $50 \mathrm{MPa}$ is applied on the broad surface of the cable (in the vertical direction in Fig. 4). In the center sections, the contact surface is parallel to the pressure (see Fig. 4), whereas the contact surfaces in the edge sections also have a component perpendicular to the applied pressure. Taking both contact surface and pressure into account we can conclude that both $k_{\text {is }}$ and $R_{\mathrm{a}}$ will vary considerably at the edges, possibly by one order of magnitude.

Our cable is a LHC type II cable and because it has a $13 \mathrm{~mm}$ wide, $25 \mu \mathrm{m}$ thick stainless steel core, the compaction factor will be even higher. This results in a decrease in $A_{\mathrm{He}, \mathrm{i}}$ and $v_{\mathrm{i}}$, and an increase in $A_{\mathrm{a}}$. Although there are differences in the geometry between the measured cable (cored LHC type II) and the described cable (un-cored LHC type I), we believe that the qualitative change in geometry over the width of the cable applies for the measured cable too.

Measurements have shown that, even after final heat treatment, the RRR-value can vary more than $20 \%$ over the cable width [9]. The local RRR values on extracted strands from the investigated cable was measured and accounted for in the simulations.

\section{Results AND SimUlations}

In Fig. 6 the QE versus $I / I_{C}$ curves are shown for the five different positions on the sample. Note that in Regime I, the curves are all about the same with all values within $\pm 20 \%$. The differences can be explained by the variation in heaters [7]. More clear is the difference in the position of the kink between the different positions. The figure shows a gradual change in the kink position from $I / I_{\mathrm{c}}=0.68$ to $I / I_{\mathrm{c}}=0.82$, with in general the highest QE for the center heater 3 and the lowest QE for the thin edge heater 5 . Besides, there is a factor of 4 difference in

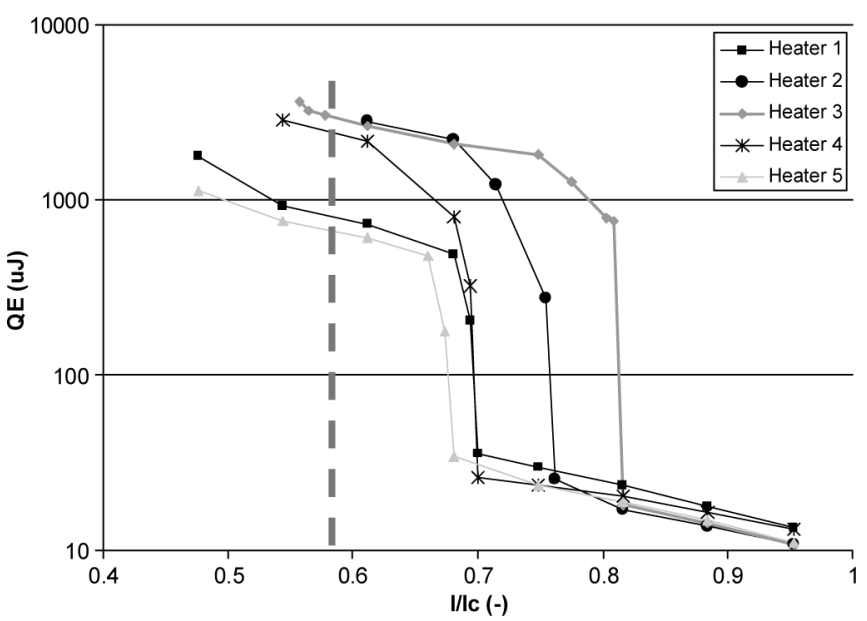

Fig. 6. The quench energy curves for 5 different positions across the width on a Rutherford cable. The dashed line shows the operating point of FAIR SIS-300 at $4.7 \mathrm{~K}$ at $I / I_{\mathrm{c}}=0.58$.

quench level at $I / I_{\mathrm{C}}=0.61$. It is important to note that the thin and thick edges of the cable have very similar stability behavior.

In Regime I the cable stability behaves like single strand stability. Therefore, current redistribution and $R_{\mathrm{a}}$ play no role. From the hot spot the heat must redistribute by using helium cooling $\left(A_{\mathrm{He}}\right)$, longitudinal heat distribution through the strand (where RRR is important) and to a lesser extent interstrand heat distribution (through $A_{\mathrm{a}}$ and $A_{\mathrm{cr}}$ ). Normally in this regime only small pulses (up to $50 \mu \mathrm{J}$ ) are used and the helium cooling is limited not by its volume $V_{\mathrm{He}}$ but by its surface $A_{\mathrm{He}}$.

The cable stability in Regime II is governed by two equally important mechanisms, namely the current redistribution and the heat distribution in the cable. In the network model CUDI the cable is discretized into small strand sections with length $d x$ and both the currents and temperatures are solved in time. The electrical model is based on solving a set of Kirchhoff equations, comprising the currents in the strand sections $\left(I_{\mathrm{S}}\right)$, in the adjacent contacts $\left(I_{\mathrm{a}}\right)$, and in the cross-contacts $\left(I_{\mathrm{cr}}\right)$. Note that for this cable $I_{\text {cr }}$ can be neglected because $R_{\mathrm{a}} \ll R_{\mathrm{c}}$. For each section the main equation that needs to be solved in the thermal model for every small time step $\Delta t$ is:

$$
\begin{array}{r}
c_{p} \frac{\Delta T_{s, t}}{\Delta t} V_{s}=P_{i n p}-k_{H e}\left(T_{s}-T_{H e}\right) A_{H e}+I_{s}^{2} R_{s}+I_{a}^{2} R_{a} \\
-k_{\mathrm{is}}\left(T_{s}-T_{a}\right) A_{a}-k_{s} \frac{\Delta T_{s, x}}{\Delta x} A_{s}
\end{array}
$$

With $c_{\mathrm{p}}$ the specific heat, $T_{\mathrm{s}}$ the temperature, $\Delta T_{\mathrm{s}, \mathrm{t}}$ the temperature change during $\Delta t, V_{\mathrm{s}}$ the volume, $R_{\mathrm{s}}$ the resistance, $k_{\mathrm{s}}$ the thermal conductivity, and $A_{\mathrm{s}}$ the cross-section of the strand. $P_{\text {inp }}$ is the power from the external heat pulse, $k_{\mathrm{He}}$ the heat conductivity to the helium, $T_{\mathrm{He}}$ the helium temperature, $T_{\mathrm{a}}$ the temperature of the adjacent strand, and $\Delta T_{\mathrm{s}, \mathrm{X}}$ the temperature change along one section. Except for $k_{\text {is }}$ all parameters in (1) are known, either from the cable characteristics, or from the previously described tomography results, or from direct measurements. Here a previously deduced value for $k_{\mathrm{He}}[5]$ is used, which is taken constant across the cable width, because the surface treatment is uniform over the entire cable. We assume that 
TABLE III

USED AND OBTAINED FREE PARAMETERS

\begin{tabular}{cccccc}
\hline \hline $\begin{array}{c}\text { Heater } \\
\text { number }\end{array}$ & RRR & $\begin{array}{c}A_{\mathrm{He}, \mathrm{i}} \\
{\left[\mathrm{mm}^{2}\right]}\end{array}$ & $\begin{array}{c}V_{\mathrm{He}, \mathrm{i}} \\
{\left[\mathrm{mm}^{3}\right]}\end{array}$ & $\begin{array}{c}A_{\mathrm{a}} \\
{\left[\mathrm{mm}^{2}\right]}\end{array}$ & $\begin{array}{c}f_{\text {is }} \\
{\left[\mathrm{W} / \mathrm{m}^{2} / \mathrm{K}^{\mathrm{n}}-\mathrm{is}\right]}\end{array}$ \\
\hline 1 & 269 & 207 & 5.5 & 249 & 45 \\
2 & 245 & 379 & 13.8 & 129 & 29 \\
3 & 245 & 641 & 12.4 & 145 & 30 \\
4 & 245 & 138 & 4.8 & 161 & 9 \\
5 & 227 & 110 & 4.1 & 273 & 53 \\
\hline \hline
\end{tabular}

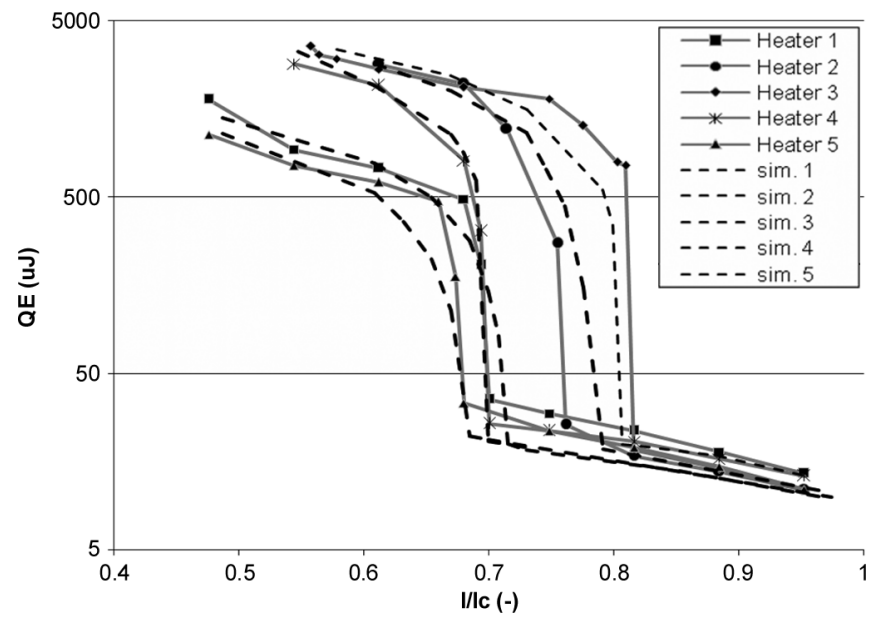

Fig. 7. Measured QE data curves in solid gray lines, along with the simulated curves in black dashed lines.

the inner voids are filled with helium, so the helium volume in $\mathrm{mm}^{3}$ per meter of strand $V_{\mathrm{He}, \mathrm{i}}=v_{\mathrm{i}}$ is taken.

At the cable edges both the interstrand resistance and the interstrand heat conductivity are influenced by the geometry. For our specific cable sample we measured an average $R_{\mathrm{a}}=$ $650 \mu \Omega$, which is relatively high. In our simulations we noticed that the current redistribution takes place over about $200 \mathrm{~mm}$ of cable, equivalent to about 100 adjacent contacts. We therefore simulate the cable with constant $R_{\mathrm{a}}$ instead of making it a function of the position across the cable. The heat redistribution is however much more local and usually the normal zone does not exceed $10 \mathrm{~mm}$ of strand length at the quench decision moment. We assume $k_{\text {is }}$ varies due to the pressure variation and use:

$$
\mathrm{k}_{\mathrm{is}}=\mathrm{f}_{\mathrm{is}} \cdot \mathrm{T}^{\mathrm{n}_{i s}},
$$

with $f_{\text {is }}\left[\mathrm{W} / \mathrm{m}^{2} / \mathrm{K}^{\mathrm{n}-\text { is }}\right]$ as a free parameter and $n_{\text {is }}=2.25$ [5]. Using the curves in Fig. 5 and values we take from [10] we fix the values for $A_{\mathrm{a}}$ and $V_{\mathrm{He}, \mathrm{i}}$ as listed in Table III. We accounted for the core volume by subtracting it evenly from $\mathrm{V}_{\mathrm{He}}$ for the middle $13 \mathrm{~mm}$ of the cable. We used $A_{\mathrm{He}, \mathrm{i}}$ as a free parameter because we expect it to be locally influenced by the core that can creep into the inner voids. We have compared $A_{\mathrm{He}, \mathrm{i}}$ with the tomography measurement.

Fig. 7 shows the curves that fit the measured data the best. With only two free parameters and three parameters that are fixed but vary between the curves, we are able to fit the measured curves properly. During the simulations and as shown in parameter sensitivity plots in [5] we noticed that the position of the kink is almost insensitive to variations of $f_{\text {is }}$. Because heater 4 shows a low $I_{\text {kink }}$ and yet a high amplitude in Regime II, $A_{\mathrm{He}, \mathrm{i}}$ and $f_{\text {is }}$ are both small as compared to heaters 2 and 3 . As expected due to the higher pressure the value for $f_{\text {is }}$ for heater 1 and 5 is higher by almost a factor of two as compared to heater 2 and 3 and even more as compared to heater 4 .

\section{CONCLUSIONS}

Measurement of the stability of several superconducting Rutherford cables exposed to short point-like heat pulses on strands show that the edge of a cable is significantly less stable than the central part of the cable. Analysis with neutron tomography of the cable cross-section shows that the interstrand contact surface, void fraction, and the contact surface between strand and helium vary strongly.

Although it is widely assumed that the stability at the thin edge is much worse compared to the thick edge due to a decreased void fraction, the measurements show that there is only a minor difference. From a stability point of view it is therefore not important to minimize the keystone angle.

In the design of a cable for accelerator magnets the most critical issue determining stability are the cable edges. To increase stability a decrease in contact surface between adjacent strands $\left(A_{\mathrm{a}}\right)$, thermal conductivity $\left(\mathrm{k}_{\mathrm{is}}\right)$ and especially an increase in area filled with helium $\left(A_{\mathrm{He}}\right)$ are needed. A big gain may be accomplished by leaving the outer surfaces on the edges accessible to helium.

\section{REFERENCES}

[1] A. Gosh, W. Sampson, and M. Wilson, "Minimum quench energies of Rutherford cables and single wires," IEEE Trans. Appl. Supercond., vol. 7, p. 1051, 1997.

[2] S. Kim, D. Leroy, M. Wilson, A. Gosh, and W. Sampson, "Stability measurements of Rutherford cables with various treatments," IEEE Trans. Appl. Supercond., vol. 9, p. 1145, 1999.

[3] A. P. Verweij et al., "1.9 K test facility for the reception of the superconducting cables for LHC," IEEE Trans. Appl. Supercond., vol. 9, p. $153,1999$.

[4] G. Willering et al., "Investigation of local stability behaviour of superconducting nbti rutherford cables by measurements and simulations with point-like heaters," CERN AT-MAS internal note 2006-04, EDMS 788864, 2006

[5] G. Willering, A. Verweij, J. Kaugerts, and H. Ten Kate, "Stability of $\mathrm{Nb}-\mathrm{Ti}$ Rutherford cables exhibiting different contact resistances," this conference.

[6] A. Verweij, "CUDI: A model for calculation of electrodynamic and thermal behaviour of superconducting Rutherford cables," Cryogenics, vol. 46, no. 7-8, p. 619, 2006, Used version 0701.

[7] G. Willering and A. Verweij, "Modeling the heat flow from a graphite paste heater used for cable stability measurements," CERN AT-MCS, internal note 2007.

[8] T. Shimada et al., "Manufacturing of superconducting cable for the LHC - Key technology and statistical analysis," IEEE Trans. Appl. Supercond., vol. 12, pp. 1075-1078, 2002.

[9] Z. Charifoulline, "Local RRR measurements in the superconducting strands extracted from LHC cables," CERN, unpublished, 2000.

[10] J. Depond et al., "Superconducting cable topology," CERN LHC-MMS internal note 97-04, 1997. 